\title{
EVALUATION OF GFP-BASED SYSTEM FOR PRE-CRYSTALLISATION STUDY OF EgKUP MEMBRANE PROTEINS
}

MOHD NAQIUDDIN* and MEILINA ONG ABDULLAH*

\begin{abstract}
Elucidation of atomic structures of membrane proteins $(M P)$ is of great importance for comprehensive understanding of their functions and mechanism of actions. Determination of high resolution protein structures by X-ray crystallography requires crystallisation of a protein of interest. Obtaining wellordered protein crystals however, is not an easy task and many factors can contribute to unsuccessful crystallisation. The situation will get much trickier when dealing with MP owing to the fact that they are not soluble in their innate state after extraction from the lipid bilayer environment. Unless appropriate detergents are used to stabilise proteins by mimicking their native environment, MP tend to unravel, thus becoming dysfunctional. This study evaluates the effectiveness of using Green Fluorescence Protein (GFP)-based system as C-terminal tag in Saccharomyces cerevisiae for pre-crystallisation study of Elaeis guineensis MP from the $\underline{K}^{+} \underline{\text { Transporter/ }} \underline{\mathrm{K}}^{+} \underline{\text { Uptake }} \underline{\text { Permease/High }} \underline{\text { Affinity }} \underline{\mathrm{K}}^{+}(\mathrm{KT} / \mathrm{KUP} /$ HAK) superfamily. KT/KUP/HAK are one of the most important MP responsible for potassium uptake in plants. Development of recombinant expression system for high-level protein production is necessary as the vast majority of MP cannot be obtained in sufficient quantities from their native environment. The precrystallisation analyses were conducted on three EgKUP-GFP fusions, namely EgKUP3-GFP, EgKUP8GFP and EgKUP11-GFP. The analyses involved whole-cell florescent count of each fusion protein using spectrofluorometer, protein integrity assay by SDS-PAGE, cellular localisation by confocal fluorescence microscopy and effects of various detergents towards EgKUPs' stability and monodispersity using Fluorescence Size Exclusion Chromatography (FSEC). Results from the evaluation, associated problems and proposed troubleshootings are discussed.
\end{abstract}

Keywords: pre-crystallisation, membrane protein, KT/KUP/HAK transporters.

Date received: 15 May 2018; Sent for revision: 17 May 2018; Received in final form: 7 September 2018; Accepted: 8 January 2019.

\section{INTRODUCTION}

The $\underline{\mathrm{K}}^{+}$Transporter/ $\underline{\mathrm{K}^{+}} \underline{\text { Uptake }} \underline{\text { Permease } / \underline{\text { High }}}$ Affinity $\underline{K}^{+}(\mathrm{KT} / \mathrm{KUP} / \mathrm{HAK})$ family of potassium transporters is one of the most important membrane

*alaysian Palm Oil Board,

6 Persiaran Institusi, Bandar Baru Bangi,

43000 Kajang, Selangor, Malaysia.

E-mail: naqi@mpob.gov.my proteins (MP), responsible for potassium uptake. In plants, a few members of the KT/KUP/HAK transporters have been demonstrated to play a key role in potassium acquisition particularly when $\mathrm{K}^{+}$availability is low (Banuelos, 2002; RodriguezNavarro, 2006; Gierth, 2005; Martínez-Cordero et al., 2004; Santa-Maria et al., 1997; Wang, 2002). There are also evidences that members of KT/ KUP/HAK transporters are involved in diverse physiological functions such as complementing 
the role of $\mathrm{K}^{+}$-channels for low-affinity $\mathrm{K}^{+}$-transport (Fu and Luan, 1998; Rigas et al., 2001; Husri and Ong-Abdullah, 2018), response to salinity (Senn et al., 2001; Garciadeblas et al., 2002; Takahashi et al., 2007) and regulation of cell size (Elumalai et al., 2002; Grabov, 2007). Despite their physiological importance, our understanding on KT/KUP/HAK membrane transporters remains limited due to difficulties in working with this class of proteins.

In general, MP have diverse roles in cell physiology such as facilitating and trafficking solute exchange, signal transduction, and catalysis of enzymatic reactions (Jagannathan et al., 2010; Ubarretxena-Belandia and Stokes, 2010). They constitute almost one-third of the whole proteome of all organisms (Krogh et al., 2001) and represent 60\% of drug targets (Yildirim et al., 2007). The KT/KUP/ $H A K$ multigene family of potassium transporters is one of the most important MP in plants responsible for potassium uptake. Members of this family involve in many crucial roles in plants including high-affinity potassium $\left(\mathrm{K}^{+}\right)$acquisition (Banuelos, 2002; Rodríguez-Navarro, 2000; Santa-Maria et al., 1997), complementing $\mathrm{K}^{+}$-channel for low-affinity $\mathrm{K}^{+}$uptake (Garciadeblas et al., 2002; Senn et al., 2001), plant responses to salinity (Maathuis, 2006; Banuelos et al., 1995) and regulation of cell size (Elumalai et al., 2002). Despite their fundamental importance, our knowledge of MP structure and function remains limited due to difficulties in working with these types of proteins. According to the Protein Database (PDB) website, there were only 803 unique MP structures successfully elucidated at the time of paper submission, comprising less than $0.5 \%$ out of more than 100000 entries in the PDB. Numerous factors are known to contribute to lack of structures of MP. The hydrophobic nature of MP makes them unstable outside the lipid bilayer environment, prone to denaturation and aggregation even in the presence of stabilising detergents. Even if stable protein can be obtained, it is often very difficult to generate crystals and those that are obtained typically diffract poorly. However, the first issue encountered is that most MP are produced natively at very low levels (Nannenga et al., 2013) and thus it is essential to develop recombinant expression systems for the high level protein production required for structural studies. Selection of an appropriate heterologous expression system to produce sufficient quantities of homogenous protein and generation of a suitable expression construct are amongst the first obstacles encountered by researchers attempting structural studies on MP.

Amongst popular cellular hosts for high-level MP overexpression and subsequent purification are Escherichia coli (Wang et al., 2003; Sahdev et al., 2008) and the yeasts; Saccharomyces cerevisiae (Bill, 2001) and Pichia pastoris (Macauley-Patrick et al., 2005). Each of these systems has their advantages and disadvantages in terms of protein yield, protein folding and post-translational modification. For example, heterologous expression of eukaryotic MP in prokaryotic hosts (such as E. coli) has been successful in a number of cases (Egloff et al., 2014; Löw et al., 2012). However, issues including different lipid bilayer composition and protein processing machinery between the bacterial and eukaryotic cells can have major implications with respect to expression, folding, assembly, and stability of eukaryotic membrane proteins (Grisshammer et al., 2005; Jana and Deb, 2005). Using eukaryotic systems (such as yeasts) to express eukaryotic MP is not straight forward either. Yeasts, despite having protein processing and post-translational modification mechanisms similar to those found in higher eukaryotes (Midgett and Madden, 2007), still show great variation when expressing recombinant proteins (Hino et al., 2012; Tate et al., 2003). Therefore, selection of a suitable host system remains a matter of trial and error especially with regards to the expression level of functional protein (Midgett and Madden, 2007) and it is highly protein dependent. Next, the selection of reporter systems should also be considered. One system with a strong track record in the expression of MP employs Green Fluorescence Protein (GFP), in the form of a C-terminal, protease-cleavable and $\mathrm{His}_{6-10}$ tag. The presence of the GFP-His tag allows expression levels to be estimated by GFP fluorescence of the whole cell. Subsequently, the integrity of the GFP fusion protein can be confirmed by in-gel fluorescence using standard SDS-PAGE gel since the GFP remains folded in the presence of SDS (Drew et al., 2008).

Once the suitable host and desirable expression level were obtained, the next obstacle in MP studies is choosing appropriate detergents/amphiphiles. Detergents are amphiphatic molecules, which share the same dual hydrophobic and hydrophilic characteristics as membrane lipids and MP (le Maire et al., 2000; Prive, 2007; Seddon et al., 2004; Garavito and Ferguson-Miller, 2001). In this sense, detergents are used to imitate the native environment in providing curvature stress and lateral pressure, important for structural stabilisation and maintenance of MP topology (Booth, 2005). Detergents are applied to both extract MP from the lipid bilayer and maintain the proteins in solution for further manipulation and isolation. The use of detergents allows us to perform detailed analysis of MP in their folded and functional state outside the lipid environment, as well as to explore their interactions with other proteins (Le Maire et al., 2000). The process of selecting suitable detergents for GFP-tagged MP can be expedited by using Fluorescence Size Chromatography (FSEC). FSEC is robust, simple and less laborious as it does not require extensive purification (Kawate and Gouaux, 
2006; Newstead et al., 2007). Another advantage of using FSEC is that FSEC conditions (i.e. type of detergent and its concentration, buffer content etc.) may directly be applied for protein purification using Size Exclusion Chromatography (SEC) in the later stage (Kawate and Gouaux, 2006).

The GFP-based expression system in yeast host has been proven successful for other plant MP such as the boron transporter (Bor1) from $A$. thaliana (Takano et al., 2002). This article evaluates the suitability of using GFP-based expression system in $S$. cerevisiae for recombinant expression and subsequent pre-crystallisation assays of E. guineensis $\mathrm{KT} / \mathrm{KUP} / \mathrm{HAK}$ potassium transporters (EgKUP). Results from the evaluation, associated problems and proposed troubleshooting steps are discussed.

\section{MATERIALS AND METHODS}

\section{Gene-vector Construction and Subsequent Transformation into S. cerevisiae Strain FGY217}

Oligonucleotide primers with flanking regions homologous to the vector sequence, indicated by bold fonts (Table 1) were designed to amplify the EgKUP, applying standard PCR protocol. The individual amplified EgKUP gene was cloned into the vector pDDGFP-2 (Figure 1) by homologous recombination in S. cerevisiae cells strain FGY 217.
The EgKUP gene was C-terminally fused with a His-tagged yeast-enhanced $g f p$ gene and its expression was under the control of GAL1 promoter. Transformation was carried out by dispensing 50 $\mu \mathrm{l}$ of the $S$. cerevisiae competent cells into $1.5 \mathrm{ml}$ Eppendorf tubes containing $240 \mu$ cold sterile 50\% (w/v) polyethylene glycol (PEG) 3350. An amount of $25 \mu \mathrm{l}$ of $2 \mathrm{mg} \mathrm{ml}^{-1}$ single-stranded carrier DNA from salmon sperm (Sigma) was then added and the mixture was vortexed for $5 \mathrm{~s}$. An amount of $3 \mu \mathrm{l}$ of

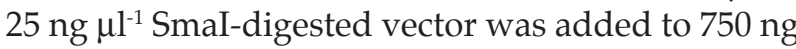
of gel-purified PCR product. The total volume was made up to $500 \mu \mathrm{l}$ with sterile water. The mixture was added to the competent cells and vortexed for a further $5 \mathrm{~s}$. The mixture was then incubated at $30^{\circ} \mathrm{C}$ for $30 \mathrm{~min}$ followed by heat-shock at $42^{\circ} \mathrm{C}$ for 25 min. The cells were pelleted by brief centrifugation and resuspended in $100 \mu$ sterile water. The cell suspension was plated onto a -URA selective plate [6.7 $\mathrm{g}$ litre $^{-1}$ yeast nitrogen base without amino acids (BD), $2 \mathrm{~g}$ litre $^{-1}$ of yeast synthetic drop-out medium without uracil (-URA) (Sigma), 2\% (w/v) glucose, and $40 \mathrm{~g}$ litre $^{-1}$ of bacteriological agar (BD)], and incubated at $30^{\circ} \mathrm{C}$ incubator for three days.

\section{Screening Colonies of EgKUP-GFP Fusions}

A single colony of each EgKUP-yeast transformant from a -URA selective plate was selected and used to individually inoculate $10 \mathrm{ml}$ of

TABLE 1. LIST OF OLIGONUCLEOTIDE PRIMERS USED TO GENERATE EgKUP-GFP FRAGMENTS FOR CLONING INTO THE PDDGFP-2 VECTOR

\begin{tabular}{ll}
\hline Primer Identification & \multicolumn{1}{c}{ Sequence $\mathbf{5}^{\prime}-\mathbf{3}^{\prime}$} \\
\hline EgKUP3-GFP-FWD & ACCCCGGATTCTAGAACTAGTGGATCCCCCATGGATCAGGAGAGAGG \\
EgKUP3-GFP-REV & AAATTGACCTTGAAAATATAAATTTTCCCCACATAGTAGATCATACCCACTTCAAT \\
EgKUP8-GFP-FWD & ACCCCGGATTCTAGAACTAGTGGATCCCCCATGGATCTCGAGGGC \\
EgKUP8-GFP-REV & AAATTGACCTTGAAAATATAAATTTTCCCCGACATGGTAAATCATCCCCACCTC \\
EgKUP11-GFP-FWD & \\
EgKUP11-GFP-REV & ACCCCGGATTCTAGAACTAGTGGATCCCCCATGGCATCGGAGACGGCAAACGAGG \\
& AAATTGACCTTGAAAATATAAATTTTCCCCTACATAGAATATCTGTCCCACA \\
\hline
\end{tabular}

Note: Font in bold represents the homologous recombination site and the normal font represents gene specific sequences.

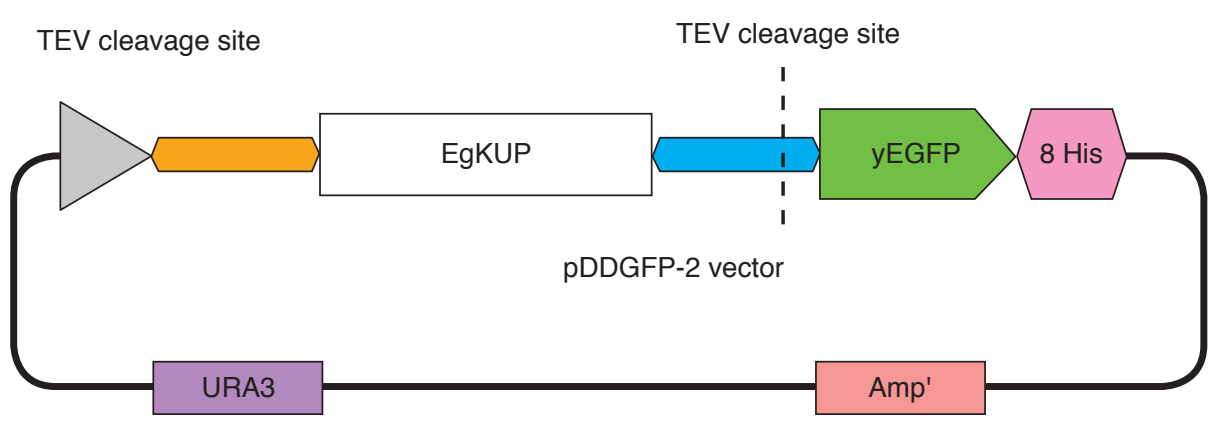

Figure 1. A schematic diagram of the vector pDDGFP-2 for expression of EgKUP. All EgKUP were amplified with flanking regions (orange and blue) homologous to the vector sequence using standard polymerase chain reaction (PCR) protocol. The individual amplified EgKUP gene was cloned into the vector by homologous recombination in S. cerevisiae cells strain FGY 217. The EgKUP gene was C-terminally fused with a His -tagged yeastenhanced gfp gene and its expression was under the control of GAL1 promoter. 
-URA broth [6.7 $\mathrm{g}$ litre ${ }^{-1}$ yeast nitrogen base without amino acids (BD), $2 \mathrm{~g}$ litre ${ }^{-1}$ of yeast synthetic dropout medium without uracil (Sigma), 2\% (w/v) glucose] in a $50 \mathrm{ml}$ aerated tube. The cultures were incubated at $30^{\circ} \mathrm{C}, 300 \mathrm{rpm}$ for overnight. Next day, $\mathrm{OD}_{600}$ measurement of the overnight cultures was taken and the culture was diluted to $\mathrm{OD}_{600} 0.12$ in a fresh $10 \mathrm{ml}$ of -URA broth containing $0.1 \%$ glucose instead of $2 \%$. The cultures were then incubated at $30^{\circ} \mathrm{C}, 300 \mathrm{rpm}$ until the $\mathrm{OD}_{600}$ reached 0.6. The $2 \%$ galactose was then added into individual tubes to induce protein expression for $22 \mathrm{hr}$ at $30^{\circ} \mathrm{C}, 300 \mathrm{rpm}$. After $22 \mathrm{hr}$, the cells were centrifuged at $3000 \mathrm{rpm}$ at $4^{\circ} \mathrm{C}$ for $5 \mathrm{~min}$. Supernatant was discarded and the cells (pellet) were resuspended in $200 \mu \mathrm{l}$ of yeast suspension buffer (YSB) [50 mM Tris- $\mathrm{HCl}$ (pH 7.5), 5 mM EDTA, $10 \%$ glycerol and one complete protease inhibitor tablet (Roche) per $50 \mathrm{ml}$ buffer]. The 200 $\mu 1$ suspension was then transferred into a 96-well plate (black Nunc 96-well optical bottom plate) for assessment of protein expression. The fluorescence was measured using a SpectraMax M2 microplate reader (Molecular devices) with emission at 512 $\mathrm{nm}$ and excitation at $488 \mathrm{~nm}$. Whole cell protein expression levels in FGY217 cells were determined from the raw fluorescent units (RFU) using the following calculation outlined by (Drew et al., 2008).

A starter culture was grown overnight at $30^{\circ} \mathrm{C}$, $280 \mathrm{rpm}$ in a $50 \mathrm{ml}$ aerated tube containing $10 \mathrm{ml}$ of -URA media supplemented with $2 \%(\mathrm{w} / \mathrm{v})$ glucose. Next day, this culture was used to inoculate 150 $\mathrm{ml}$ of -URA media supplemented with $2 \%(\mathrm{w} / \mathrm{v})$ glucose and incubated overnight at $30^{\circ} \mathrm{C}, 280$ rpm. The following day, the overnight culture was diluted to $\mathrm{OD}_{600}$ of 0.12 in a 2.5 litres baffled flask containing 1 litre of -URA media supplemented with $0.1 \%$ glucose. The culture was grown at $30^{\circ} \mathrm{C}$, $280 \mathrm{rpm}$ until the $\mathrm{OD}_{600}$ of 0.6 was reached and a final concentration of $2 \%(\mathrm{v} / \mathrm{v})$ galactose was added to induce protein expression. After $22 \mathrm{hr}$ of induction, cells were harvested by centrifugation at $4000 \mathrm{rpm}, 4^{\circ} \mathrm{C}$ for $10 \mathrm{~min}$. Cell pellets were resuspended in $25 \mathrm{ml}$ of cell resuspension buffer (CRB) [50 mM Tris-HCl (pH 7.5), 1 mM EDTA, 0.6 $\mathrm{M}$ sorbitol, and half tablet of Protease inhibitor (Roche)]. Cell lysis was performed using a heavyduty cell disruptor (Constant system) applying incremental pressures of $25,32,35,38 \mathrm{kpsi}$ at $4^{\circ} \mathrm{C}$. Unbroken cells and cell debris were removed by centrifugation at $10000 \mathrm{rpm}$ at $4^{\circ} \mathrm{C}$ for $10 \mathrm{~min}$. The supernatant containing membrane was collected and further centrifuged at $41000 \mathrm{rpm}$ at $4^{\circ} \mathrm{C}$ for $2 \mathrm{hr}$ to harvest the cell membrane. The membrane pellet was resuspended in membrane resuspension buffer (MRB) [20 mM Tris- $\mathrm{HCl}$ ( $\mathrm{pH} 7.5), 0.3 \mathrm{M}$ sucrose, $10 \%$ glycerol)] using a $100 \mathrm{ml}$ Tissue Grind Tube size homogeniser (Kimble Chase). Aliquots of $900 \mu \mathrm{l}$ were dispensed into each $1.5 \mathrm{ml}$ Beckman polyallomer microcentrifuge tubes. The aliquots of membrane suspensions were flash frozen in liquid nitrogen and stored at $-80^{\circ} \mathrm{C}$ until further use.

\section{In-gel Fluorescence from Whole Cells}

The cell suspension was transferred from the 96-well plate to a $1.5 \mathrm{ml}$ eppendorf tube. The 0.5 $\mathrm{mm}$ glass beads (Biospec) were added to make a total volume of $500 \mu \mathrm{l}$. To make a final volume of 1 $\mathrm{ml}, 500 \mu \mathrm{l}$ of ice-cold YSB was then added into the tube. The cells were subjected to lysis using a cell disruptor (Qiagen) set at $30 \mathrm{~Hz}$ for $7 \mathrm{~min}$. Samples were briefly centrifuged and the supernatant was collected into a fresh $1.5 \mathrm{ml}$ eppendorf tube. This step was done twice. The supernatant was then centrifuged at $13000 \mathrm{rpm}$ at $4^{\circ} \mathrm{C}$ for $1 \mathrm{hr}$ in order to harvest the membrane. The membrane pellet was then resuspended in $50 \mu \mathrm{l}$ of YSB. For in-gel fluorescence, $10 \mu \mathrm{l}$ of the membrane suspension was mixed with an equal volume of $2 x$ Novex in 12\% Tris-glycine SDS-PAGE buffer (Invitrogen) and individual samples loaded onto a 12-well Novex 12\% Tris-gly gel (Invitrogen). A $3 \mu \mathrm{l}$ aliquot of Benchmark fluorescent marker (Invitrogen) was used as a protein standard. The gel was then run at $225 \mathrm{~V}$ for $45 \mathrm{~min}$. Following separation, the fluorescent bands were detected using a LAS1000-3000 charged-coupled device (CCD) imaging system (Fuji film) with an excitation wavelength of $460 \mathrm{~nm}$.

\section{Confocal Fluorescence Microscopy}

Recombinant cells carrying EgKUP3, 8 and 11 were separately grown as previously described above. Twenty-two hours after induction the cells were harvested in $1 \mathrm{ml}$ of -URA media supplemented with $10 \%$ glycerol (v/v). Addition of glycerol helps to slow down yeast mobility for better quality images. An amount of $2 \mu \mathrm{l}$ of cell suspension was placed on the centre of a glass slide and a coverslip placed on top. The slide was inverted and placed on the microscope platform. The instrument used was a Leica DM-IRE inverted microscope connected to a Leica confocal TCS-SP2 AOBS. A $488 \mathrm{~nm}$ laser was used for GFP excitation, and emission was detected using a 495 - $560 \mathrm{~nm}$ window. Data were processed by Leica Control Software (LCS). Bright field and fluorescent images were captured with a 'Carl Zeiss ${ }^{\circledR}$ Axiocam Fitting' camera. Images were viewed using 'Axiovision' (version 3.1.21) (Carl Zeiss) software for PC with 'Carl Zeiss ${ }^{\circledR}$ AxioCamHR', (version 5.05.10) and 'TWAIN', (version 1.0) add-ons.

\section{Plasma Membrane Preparation for FSEC}

The membrane suspension aliquots were thawed and a final concentration of $1 \%(\mathrm{w} / \mathrm{v})$ detergent was 
added to give a total reaction volume of $1 \mathrm{ml}$. The mixture was incubated on a moving platform at $4^{\circ} \mathrm{C}$ for $1 \mathrm{hr}$ to allow solubilisation. A $100 \mu \mathrm{l}$ aliquot of each detergent-solubilised sample was taken for GFP fluorescence measurement. The remaining 900 $\mu \mathrm{l}$ was centrifuged in a benchtop ultracentrifuge (Beckman) at $41000 \mathrm{rpm}$ at $4^{\circ} \mathrm{C}$ for $45 \mathrm{~min}$. The supernatant containing solubilised fusion (usually less than $900 \mu \mathrm{l}$ ) was transferred into a fresh $1.5 \mathrm{ml}$ eppendorf tube. A $100 \mu \mathrm{l}$ aliquot of the solubilised fraction was taken for further GFP measurement. Solubilisation efficiency was then calculated as GFP fluorescence after ultracentrifugation/GFP fluorescence before ultracentrifugation $\times 100 \%$. From the remaining solubilised protein fusion, 500 $\mu \mathrm{l}$ was injected into a Superose $610 / 30$ column (GE Healthcare) pre-equilibrated with FSEC buffer [20 $\mathrm{mM}$ Tris- $\mathrm{HCl}$ ( $\mathrm{pH} 7.5$ ), $150 \mathrm{mM} \mathrm{NaCl}, 0.03 \%$ (w/v) $\mathrm{DDM}]$ at a flow rate of $0.4 \mathrm{ml} \mathrm{min} \mathrm{m}^{-1}$. The eluate was collected as $0.2 \mathrm{ml}$ fractions on a blank Nunc 96well optical bottom plate. The GFP fluorescence of each fraction was measured using the Softmax Pro software suite (Molecular devices) with an excitation wavelength of $488 \mathrm{~nm}$ and an emission wavelength of $512 \mathrm{~nm}$. GFP fluorescence was then plotted against the fraction numbers.

\section{RESULTS}

\section{Recombinant Expression of EgKUP-GFP Fusions in S. cerevisiae}

The expression level of EgKUP-GFP fusions is given in Table 2, based on calculation as described by Drew et al. (2008). A threshold of $\geq 1 \mathrm{mg} \mathrm{litre}{ }^{-1}$ was set as a requirement for further analyses, as suggested by Sonoda et al. (2011). From Table 2 , it is clear that the expression level of all three EgKUP-GFP fusions meets the minimum threshold requirement as pre-determined. Subsequently, the integrity of EgKUP-GFP fusions was examined by SDS-PAGE gel analysis. Results from the ingel fluorescence analysis (Figure 2) show that the sample in lane 3 gives a clear band for EgKUP3GFP of approximately $\sim 75-80 \mathrm{kDa}$ indicating that this fusion is well expressed and not subjected to degradation. The expression of EgKUP11-GFP was also observed, but with weaker intensity compared to the EgKUP3-GFP, also at approximately $\sim 75-80$ $\mathrm{kDa}$ (lanes 2, 3 and 5). In the case of EgKUP8-GFP, expression was only observed in one of the five colonies and the band obtained was much fainter $\sim 75-80 \mathrm{kDa}$ (lane 6) compared to the EgKUP3-

TABLE 2. EXPRESSION LEVELS OF EgKUP-GFP FUSIONS AS MEASURED BY GFP FLUORESCENCE

\begin{tabular}{ccccc}
\hline Protein-GFP fusion & $\begin{array}{c}\text { Molecular } \\
\text { weight of } \\
\text { EgKUP (kDa) }\end{array}$ & $\begin{array}{c}\text { Molecular weight } \\
\text { of fusion protein } \\
\text { (kDa) }\end{array}$ & $\begin{array}{c}\text { Whole cell } \\
\text { expression } \\
\text { (RFU) }\end{array}$ & $\begin{array}{c}\text { Protein expression } \\
\text { estimation } \\
(\mathbf{m g} \text { litre } \mathbf{- 1})\end{array}$ \\
\hline EgKUP3-GFP & 88.28 & 116.28 & 11809 & 1.10 \\
EgKUP8-GFP & 86.56 & 114.56 & 11340 & 1.0 \\
EgKUP11-GFP & 88.39 & 116.39 & 12949 & 1.26 \\
\hline
\end{tabular}

Note: GFP - Green Fluorescence Protein.

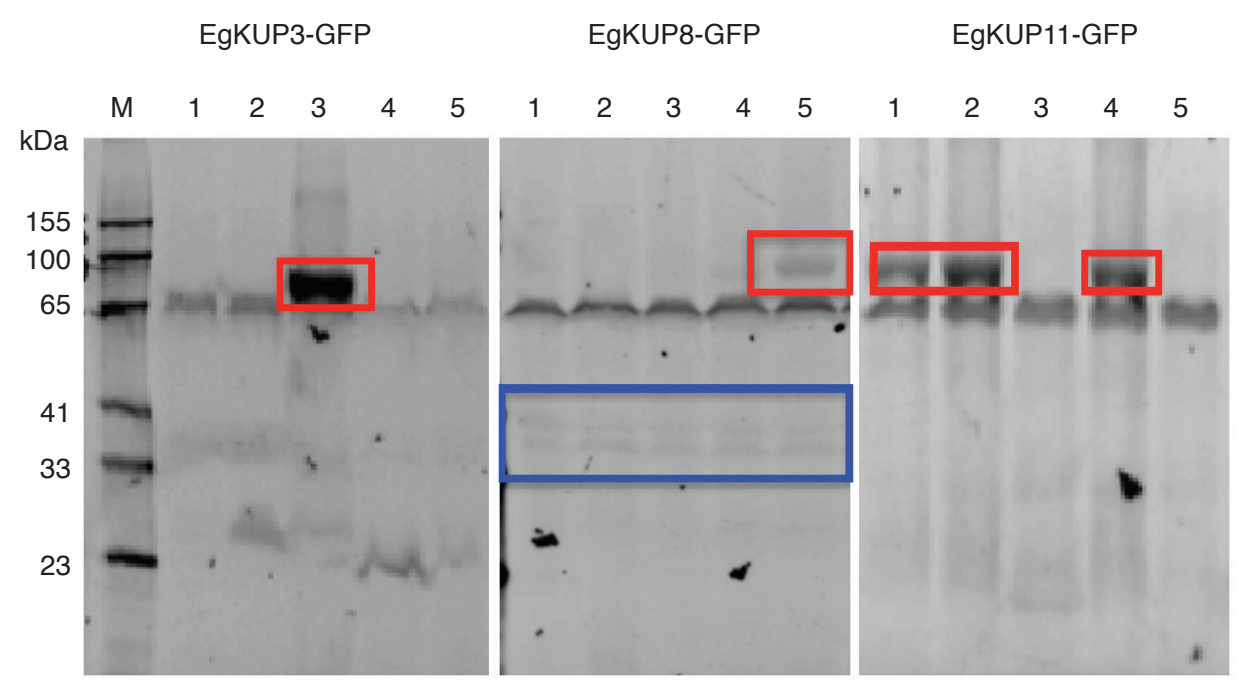

Figure 2. In-gel fluorescence of EgKUP-GFP fusion proteins expressed in S. cerevisiae. Five single FGY217 colonies from -URA selective plates were selected for small scale expression. Each colony was cultured as described in the main text and the membranes prepared and harvested. The membrane samples were separated on Novex 12\% Tris-gly gels. Lane M contains the fluorescent protein standards and lanes 1 to 5 of each protein represents crude membrane bands from the five colonies. Red rectangles show the signal from respective EgKUP-GFP fusion. The blue rectangle shows the possible degradation of EgKUP8-GFP. 
GFP and EgKUP11-GFP constructs. This probably was due to protein degradation, as indicated by appearance of smear bands inside the blue rectangle. The visible band at approximately $65 \mathrm{kDa}$ in each lane is an endogenous fluorescent 'background' protein as previously reported (Drew et al., 2008). This unknown protein is detectable in virtually all in gel fluorescence analyses of GFP fusion proteins expressed in this system. Another observation was that all the EgKUP-GFP fusions bands on the gel appeared smaller than their predicted size as described in Table 2, likely due to the phenomenon termed as 'gel-shifting' which is quite common for MP. The on-gel shifting may occur at the rate of $10 \%$ to $30 \%$ from the actual formula weights of a protein (Rath et al., 2009).

\section{Celullar Localisation via Confocal Fluorescence Microscope}

Despite meeting the minimum threshold of expression level, very few cells expressed GFP as visualised (Figure 3). This discrepancy may be caused by overestimation of the protein expression level or it could be the overexpression of the target protein was toxic to the cell. Details of possibilities are discussed in the Discussion section. Another observation made was that none of the EgKUPGFP fusions localised to the plasma membrane as expected (Figure 3). Comparison with the detailed localisation studies of eukaryotic GFP fusion proteins expressed in $S$. cerevisiae as conducted by (Newstead et al., 2007) indicated that EgKUP3-GFP and EgKUP8-GFP localise to the ER, while EgKUP11GFP is likely to be localised to the cytoplasm. In both cases, it is an indication that the protein is misfolded and retained in the ER (as observed for EgKUP3- and EgKUP8-GFP) or dislocated from the ER and degraded by the proteasome in the cytosol (as probably observed for EgKUP11-GFP) (Ellgaard and Helenius, 2003).

\section{Fluorescence Size Exclusion Chromatography}

FSEC assay was then performed to determine the solubilisation conditions that produce the most stable protein. In this experiment, a peak of homogenous

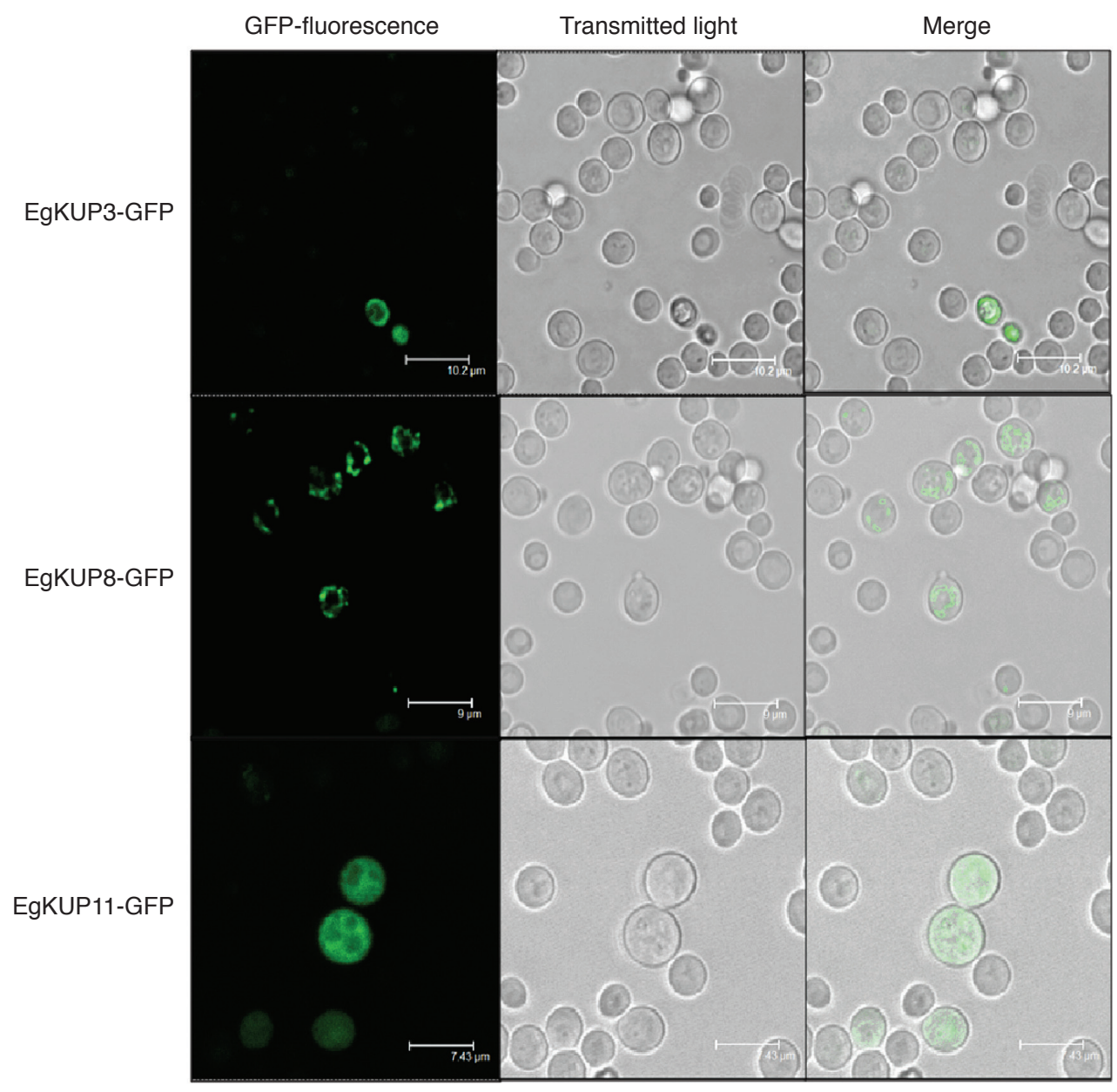

Figure 3. Confocal imaging. Representative of epifluorescent images of S. cerevisiae FGY217 cells expressing EgKUP3-, EgKUP8-, and EgKUP11-GFP using pDDGFP-2 vector after $22 \mathrm{hr}$ of galactose-induction. Cells were visualised using $40 \mathrm{X}$ magnification lenses and captured using a Carl Zeiss ${ }^{\circledR}$ camera. Bars representing scales indicated in each image read as follows: EgKUP3-GFP $=10.2 \mu \mathrm{m} ;$ EgKUP8-GFP $=9 \mu \mathrm{m} ;$ EgKUP11-GFP $=7.43 \mu \mathrm{m}$. 
and monodisperse detergent-solubilised protein fusion is desired since this criterion was suggested as a good indicator for stability, and suitability for protein purification and subsequent analyses. The definition of monodispersity taken here is a symmetrical fusion peak which is equal to or larger than the aggregation peak (Newstead et al., 2007), such as illustrated in Figure $4 d$. The EgKUP fusion proteins were solubilised in a number of detergents including $\mathrm{n}$-Dodecyl $\beta$-D-Maltopyranoside (DDM), n-decyl- $\beta$-D-maltopyranoside (DM) and Maltoseneopentyl glycol-34 (MNG-34) for FSEC analysis. Unfortunately, FSEC analysis revealed that none of the DDM-solubilised protein fusions produced monodisperse fusion judging from the absence of symmetrical peaks on the FSEC profiles (Figure 4). The absence of monodisperse EgKUP fusions might be the result of protein aggregation labelled as aggregation peak in Figure 4. Chromatogram profiles of EgKUP-GFP fusions in other detergents also revealed a lack of monodisperse protein (not shown).
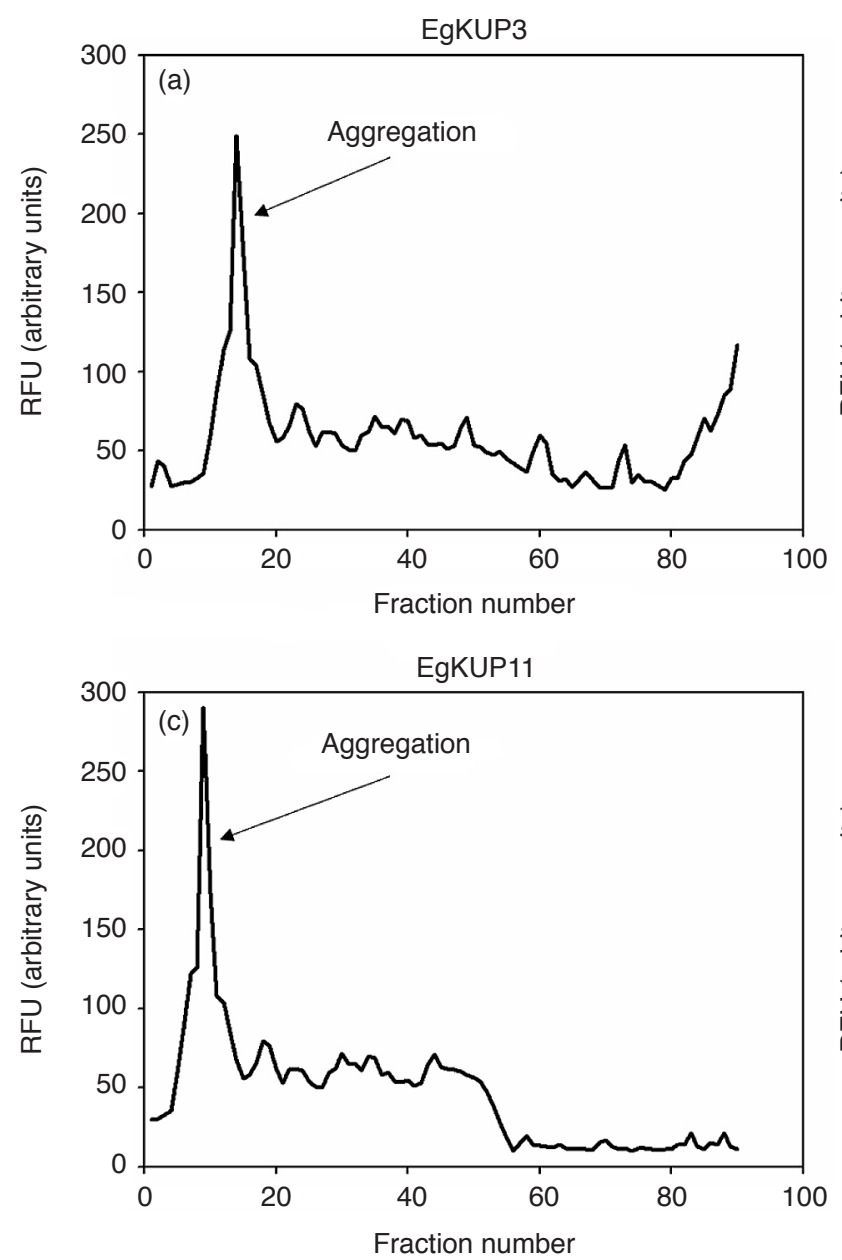

\section{DISCUSSION}

The possible reason for disagreement between the above-threshold protein levels (Table 2) and low number of cells expressing GFP (Figure 3) was potentially due to overestimation of the protein expression level. The overestimated protein level may be contributed by intracellular fluorescence. Previous work by Baker et al. (2007) indicated that fluorescent proteins (including GFP) could fold independently from the rest of the construct. This phenomenon contributes to the intracellular fluorescence thus giving false reading, indicating that GFP is properly folded but the integral MP region may not, leading to retention in the endoplasmic reticulum (ER) (Baker et al., 2007). This phenomenon may also explain the localisation of EgKUP as observed in Figure 3. The low number of cells expressing GFP (Figure 3) could also be associated with the expressed protein becoming toxic upon expression in yeast (Van Criekinge and Beyaert, 1999). The attempt to express very high
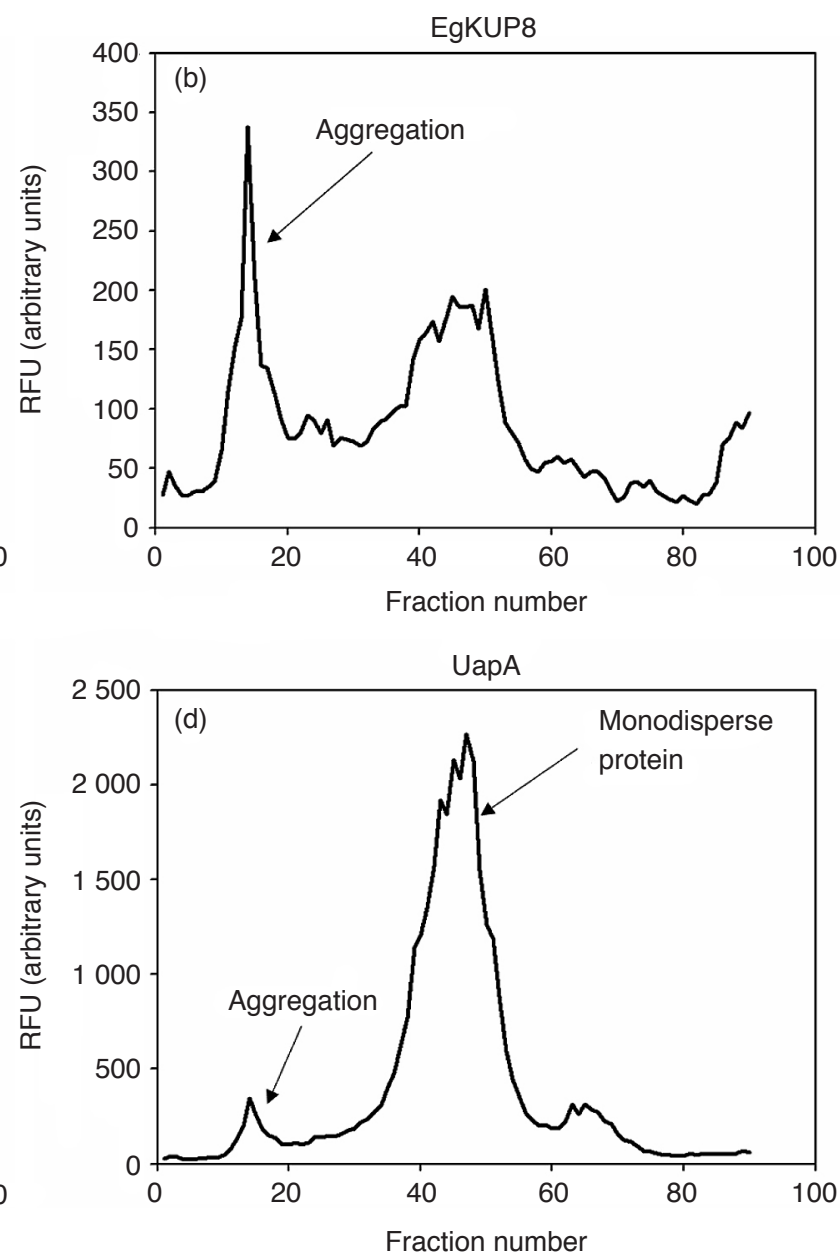

Figure 4. Fluorescence Size Exclusion Chromatography (FSEC) profiles of EgKUP-GFP solubilised in DDM. EgKUP-GFP were separately solubilised in buffer containing DDM and loaded onto a DDM-pre-equilibrated Superose 6 column. (a) EgKUP3-GFP, (b) EgKUP8-GFP and (c) EgKUP11-GFP. FSEC shows no monodisperse peak of any of EgKUP-GFP. (d) Example of desired monodisperse protein peak for protein-GFP fusion, produced using the similar GFP system and FGY217 strain. 
levels of protein using a comparatively strong promoter like GAL1 (Partow et al., 2010) might have overwhelmed the cells with too much protein production, exceeding the capacity that they can cope with (Van Criekinge and Beyaert, 1999). In addition, the presence of the C-terminal GFP tag may also inhibit effective expression, folding and/ or interrupts trafficking of the protein (Baker et al., 2007).

The above-mentioned factors may contribute to unfavourable FSEC profiles (Figure 4). Despite meeting the minimum expression threshold, it was not possible to obtain soluble protein as indicated by the presence of aggregation peak and absence of monodisperse protein fusion peak in the chromatograms (Figure 4). Previous studies on plant transporters expressed in GFP-based system in S. cerevisiae found only 17 out of 41 expressed more than $1 \mathrm{mg} \mathrm{litre}^{-1}$ and only $58 \%$ of these yielded monodisperse detergent-solubilised proteins as assessed by FSEC analysis (Sonoda et al., 2011). Based on the FSEC results, it is suggested that future work should not only rely on numerical data from equation-based calculation, rather it has to be combined with visualisation of the pre-tagged target proteins for a more conclusive insight.

Another possible contributor to the poor performance of EgKUP expression reported here might have been the $S$. cerevisiae system itself. There were a number of studies reported that S. cerevisiae system was not suitable for expression of plant transporters. For example HvHAK2 was reported non-functional in $S$. cerevisiae (Senn et al., 2001). Experiences from our own laboratory in expressing A. thaliana KUP as protein-GFP fusions in $S$. cerevisiae have also demonstrated almost similar behaviour as observed in expression of EgKUP (data not shown). The possible reason that plant membrane transporters are frequently not functional in S. cerevisiae is due to failure of the host system to recognise the regulation of the transporter or the protein is not correctly targeted to the plasma membrane (Garciadeblas et al., 2007; Rubio et al., 2000; Villalba et al., 1992). Although the mechanisms underlying the trafficking of proteins to the plasma membrane are still unclear, proper folding of monomers and subsequent assembly into oligomers are often a prerequisite for a protein to be transported from the ER (Villalba et al., 1992).

\section{FUTURE PERSPECTIVES}

Since there is no prior structural knowledge on plant KUP, a possible measure that could be considered for future work is to improve the level of expression and protein yields of EgKUP by performing random mutagenesis. Random mutagenesis and subsequent screening of mutant libraries has been exploited to enhance protein expression and yield of integral MP (Molina et al., 2008). It is also a useful approach for improving the properties of proteins (such as stability), investigating structure-function relationships and studying the mechanisms of molecular evolution (Bloom et al., 2005; Johannes and Zhao, 2006). It has been demonstrated that the protein yields of five out of nine tested recombinant proteins have successfully been improved following a single cycle of random mutagenesis, in which one of them showed 40-fold increase in yield of detergent-solubilise protein (Molina et al., 2008). Production of truncated version of a target protein may also help to increase level of expression and to improve protein folding. For instance, the turkey $\beta$-adrenergic receptor ( $\beta$ AR) with truncated $C$-termini demonstrated increased expression, improved detergent solubilisation and retention of regulatory activity (Parker and Ross, 1991). Construction of $\mathrm{N}$ - or/and C-terminally truncated constructs to remove possible unstructured region at protein terminal was also shown to significantly improve protein expression level (Leung et al., 2013) as well as protein stability (Manieri et al., 2003).

Despite many advantages of using the GFPtag system, a relatively large molecule of the GFP itself (238 amino acid residues) could potentially alter the intrinsic properties of the target protein, affecting MP expression and stability (Fucile et al., 2002; Rodriguez-Banqueri et al., 2012). Whether this was the reason for the relatively low expression and instability of the EgKUP is not clear. Future work may want to explore the use of split-GFP system. This system co-expresses two plasmids; the first plasmid carries the fluorescing part of GFP, which is the first 15 residues, and fused to the C-terminus of a target protein, and the second plasmid carries the remaining GFP residues. Application of the splitGFP system has been demonstrated to reduce the risk of GFP interference (Fucile et al., 2002; RodriguezBanqueri et al., 2012). Switching to E. coli system may also be one of the alternatives considering that it was possible to express functional EgKUP in E. coli (Husri and Ong-Abdullah, 2018). Using E. coli as an expression system to characterise KT/KUP/ HAK transporters was also proven successful for the barley HvHAK2 (Senn et al., 2001).

\section{CONCLUSION}

At present very little information is known with regards to residues responsible for $\mathrm{K}^{+}$uptake, binding, sensing of deficiency and selectivity of $\mathrm{K}^{+}$ over $\mathrm{Na}^{+}$in plants, let alone in E. guineensis. Therefore a detailed structure-function knowledge of EgKUP is required for better understanding of the $\mathrm{K}^{+}$uptake and regulation in the oil palm. This study evaluates the use of GFP-based system for pre-crystallisation 
of EgKUP for structural characterisation study. In summary, the use of C-terminal GFP system for recombinant expression of EgKUP in $S$. cerevisiae yielded low number of cells expressing GFP and incorrect localisation of the MP, probably as a result of protein misfolding and retention in the ER or that the protein being dislocated from the ER and degraded by the proteasome in the cytosol. Owing to these factors, attempts to obtain monodisperse MP fusions were unsuccessful and most of the fusions ended up as aggregates. Modifications of the approach for future improvement have also been presented.

\section{ACKNOWLEDGEMENT}

This research was financially supported by MPOB. The authors wish to thank the Director-General of MPOB for permission to publish this work. We thank Prof Bernadette Byrne of Imperial College, London, United Kingdom who provided insight and expertise that greatly assisted the research. We are also grateful to the staff at the Molecular Biosciences Imperial College, London, United Kingdom, and, Advanced Biotechnology and Breeding Centre $\mathrm{MPOB}$ for their co-operation and assistance.

\section{REFERENCES}

Baker, B J; Lee, H; Pieribone, V A; Cohen, L B; Isacoff, E Y; Knopfel, T and Kosmidis, E K (2007). Three fluorescent protein voltage sensors exhibit low plasma membrane expression in mammalian cells. J. Neurosci Methods, 161: 32-38.

Banuelos, M A (2002). Inventory and functional characterization of the HAK potassium transporters of rice. Plant Physiol., 130: 784-795.

Banuelos, M A; Klein, R D; Alexander-Bowman, S J and Rodriguez-Navarro, A (1995). A potassium transporter of the yeast Schwanniomyces occidentalis homologous to the Kup system of Escherichia coli has a high concentrative capacity. EMBO J., 14: 30213027.

Bill, R M (2001). Yeast - A panacea for the structurefunction analysis of membrane bllproteins? Curr. Genet, 40: 157-171.

Bloom, J D; Meyer, M M; Meinhold, P; Otey, C R; Macmillan, D and Arnold, F H (2005). Evolving strategies for enzyme engineering. Curr. Opin. Struct. Biol., 15: 447-452.

Booth, P J (2005). Sane in the membrane: designing systems to modulate membrane proteins. Curr. Opin. Struct. Biol., 15: 435-440.
Drew, D; Newstead, S; Sonoda, Y; Kim, H; Von Heijne, G and Iwata, S (2008). GFP-based optimization scheme for the overexpression and purification of eukaryotic membrane proteins in Saccharomyces cerevisiae. Nat. Protoc., 3: 784-798.

Egloff, P; Hillenbrand, M; Klenk, C; Batyuk, A; Heine, P; Balada, S; Schlinkmann, K M; Scott, D J; Schütz, M and Plückthun, A (2014). Structure of signaling-competent neurotensin receptor 1 obtained by directed evolution in Escherichia coli. Proc. Natl. Acad. Sci. USA, 111: E655-E662.

Ellgaard, L and Helenius, A (2003). Quality control in the endoplasmic reticulum. Nat. Rev. Mol. Cell Biol., 4: 181-191.

Elumalai, R P; Nagpal, P and Reed, J W (2002). A mutation in the Arabidopsis KT2/KUP2 potassium transporter gene affects shoot cell expansion. Plant Cell, 14: 119-131.

Fu, H H and Luan, S (1998). AtKuP1: A dual-affinity $\mathrm{K}^{+}$transporter from Arabidopsis. Plant Cell, 10: 6373.

Fucile, S; Palma, E; Martinez-Torres, A; Miledi, R and Eusebi, F (2002). The single-channel properties of human acetylcholine alpha 7 receptors are altered by fusing alpha 7 to the green fluorescent protein. Proc. Natl. Acad. Sci. USA, 99: 3956-3961.

Garavito, R M and Ferguson-Miller, S (2001). Detergents as tools in membrane biochemistry. J. Biol Chem, 276: 32403-32406.

Garciadeblas, B; Barrero-Gil, J; Benito, B and Rodriguez-Navarro, A (2007). Potassium transport systems in the moss Physcomitrella patens: pphak1 plants reveal the complexity of potassium uptake. Plant J., 52: 1080-1093.

Garciadeblas, B; Benito, B and Rodriguez-Navarro, A (2002). Molecular cloning and functional expression in bacteria of the potassium transporters CnHAK1 and CnHAK2 of the seagrass Cymodocea nodosa. Plant Mol. Biol., 50: 623-633.

Gierth, M (2005). The potassium transporter AtHAK5 functions in $\mathrm{K}^{+}$deprivation-induced highaffinity $\mathrm{K}^{+}$uptake and $\mathrm{AKT} 1 \mathrm{~K}^{+}$channel contribution to $\mathrm{K}^{+}$uptake kinetics in Arabidopsis roots. Plant Physiology, 137: 1105-1114.

Grabov, A (2007). Plant KT/KUP/HAK potassium transporters: Single family - Multiple functions. Annals of Botany, 99: 1035-1041.

Grisshammer, R; White, J F; Trinh, L B and Shiloach, J (2005). Large-scale expression and purification 
of a G-protein-coupled receptor for structure determination - An overview. J. Struct. Funct. Genomics, 6: 159-163.

Hino, T; Arakawa, T; Iwanari, H; Yurugi-Kobayashi, T; Ikeda-Suno, C; Nakada-Nakura, Y; KusanoArai, O; Weyand, S; Shimamura, T; Nomura, N; Cameron, A D; Kobayashi, T; Hamakubo, T; Iwata, S and Murata, T (2012). G-protein-coupled receptor inactivation by an allosteric inverse-agonist antibody. Nature, 482: 237-240.

Husri, M N and Ong-Abdullah, M (2018). Importance of KUP8 for $\mathrm{K}^{+}$uptake in rooted plantlets of Elaeis guineensis under $\mathrm{K}^{+}$sufficient conditions. South African J. Botany, 118: 65-75.

Jagannathan, B; Dekat, S; Golbeck, J H and Lakshmi, K V (2010). The assembly of a multisubunit photosynthetic membrane protein complex: A sitespecific spin labeling EPR spectroscopic study of the PsaC subunit in photosystem I. Biochemistry, 49: 2398-2408.

Jana, S and Deb, J K (2005). Strategies for efficient production of heterologous proteins in Escherichia coli. Appl. Microbiol. Biotechnol., 67: 289-298.

Johannes, T W and Zhao, H (2006). Directed evolution of enzymes and biosynthetic pathways. Curr. Opin. Microbiol., 9: 261-267.

Kawate, T and Gouaux, E (2006). Fluorescencedetection size - Exclusion chromatography for precrystallization screening of integral membrane proteins. Structure, 14: 673-681.

Krogh, A; Larsson, B; Von Heijne, G and Sonnhammer, E L (2001). Predicting transmembrane protein topology with a hidden Markov model: Application to complete genomes. J. Mol. Biol., 305: 567-580.

Le Maire, M; Champeil, P and Møller, J V (2000). Interaction of membrane proteins and lipids with solubilizing detergents. Biochim. Biophys. Acta, 1508: 86-111.

Leung, J; Cameron, A D; Diallinas, G and Byrne, B (2013). Stabilizing the heterologously expressed uric acid-xanthine transporter UapA from the lower eukaryote Aspergillus nidulans. Mol. Membr. Biol., 30: 32-42.

Low, C; Jegerschöld, C; Kovermann, M; Moberg, P and Nordlund, P (2012). Optimisation of overexpression in E. coli and biophysical characterisation of human membrane protein synaptogyrin 1. PLoS One, 7: e38244.
Maathuis, F J (2006). The role of monovalent cation transporters in plant responses to salinity. J. Exp. Bot., 57: 1137-1147.

Macauley-Patrick, S; Fazenda, M L; Mcneil, B and Harvey, LM(2005). Heterologous protein production using the Pichia pastoris expression system. Yeast, 22: 249-270.

Manieri, W; Franchini, L; Raeber, L; Dai, S; StrittEtter, A L and Schurmann, P (2003). N-terminal truncation of the variable subunit stabilizes spinach ferredoxin: Thioredoxin reductase. FEBS Lett., 549: $167-170$

Martínez-Cordero, M; Martínez, V and Rubio, F (2004). Cloning and functional characterization of the high-affinity $\mathrm{K}^{+}$transporter HAK1 of pepper. Plant Molecular Biology, 56(3): 413-421.

Midgett, C R and Madden, D R (2007). Breaking the bottleneck: Eukaryotic membrane protein expression for high-resolution structural studies. J. Struct. Biol., 160: 265-274.

Molina, D M; Cornvik, T; Eshaghi, S; Haeggström, J Z; Nordlund, P and Sabet, M I (2008). Engineering membrane protein overproduction in Escherichia coli. Protein Sci., 17: 673-680.

Nannenga, B L;Iadanza, MG; Vollmar, BS and Gonen, T (2013). Overview of electron crystallography of membrane proteins: Crystallization and screening strategies using negative stain electron microscopy. Curr. Protoc. Protein Sci., 17: 17.15.1-17.15.11

Newstead, S; Kim, H; Von Heijne, G; Iwata, S and Drew, D (2007). High-throughput fluorescent-based optimization of eukaryotic membrane protein overexpression and purification in Saccharomyces cerevisiae. Proc. Natl. Acad. Sci. USA, 104: 1393613941.

Parker, E M and Ross, E M (1991). Truncation of the extended carboxyl-terminal domain increases the expression and regulatory activity of the avian betaadrenergic receptor. J. Biol. Chem., 266: 9987-9996.

Partow, S; Siewers, V; Bjørn, S; Nielsen, J and Maury, J (2010). Characterization of different promoters for designing a new expression vector in Saccharomyces cerevisiae. Yeast, 27: 955-964.

Prive, G G (2007). Detergents for the stabilization and crystallization of membrane proteins. Methods, 41: 388-397.

Rath, A; Glibowicka, M; Nadeau, V G; Chen, G and Deber, C M (2009). Detergent binding explains 
anomalous SDS-PAGE migration of membrane proteins. Proc. Natl. Acad. Sci. USA, 106: 1760-1765.

Rigas, S; Debrosses, G; Haralampidis, K; VicenteAgullo, F; Feldmann, K A; Grabov, A; Dolan, L and Hatzopoulos, P (2001). TRH1 encodes a potassium transporter required for tip growth in Arabidopsis root hairs. Plant Cell, 13: 139-151.

Rodriguez-Banqueri, A; Kowalczyk, L; Palacin, M and Vazquez-Ibar, J L (2012). Assessment of membrane protein expression and stability using a split green fluorescent protein reporter. Anal. Biochem., 423: 7-14.

Rodriguez-Navarro, A (2000). Potassium transport in fungi and plants. Biochim. Biophys. Acta, 1469: 1-30.

Rodriguez-Navarro, A (2006). High-affinity potassium and sodium transport systems in plants. J. Experimental Botany, 57: 1149-1160.

Rubio, F; Santa-Maria, G E and Rodriguez-Navarro, A (2000). Cloning of Arabidopsis and barley cDNAs encoding HAK potassium transporters in root and shoot cells. Physiol. Plant, 109: 34-43.

Sahdev, S; Khattar, S K and Saini, K S (2008). Production of active eukaryotic proteins through bacterial expression systems: A review of the existing biotechnology strategies. Mol. Cell. Biochem., 307: 249-364.

Santa-Maria, G E; Rubio, F; Dubcovsky, J and Rodriguez-Navarro, A (1997). The HAK1 gene of barley is a member of a large gene family and encodes a high-affinity potassium transporter. Plant Cell, 9: 2281-2289.

Seddon, A M; Curnow, P and Booth, P J (2004). Membrane proteins, lipids and detergents: Not just a soap opera. Biochim. Biophys. Acta, 1666: 105-117.

Senn, M E; Rubio, F; Banuelos, M A and RodriguezNavarro, A (2001). Comparative functional features of plant potassium HvHAK1 and HvHAK2 transporters. J. Biological Chemistry, 276(48): 4456344569.

Sonoda, Y; Newstead, S; Hu, N-J; AlgueL, Y; Nji, E; Beis, K; Yashiro, S; Lee, C; Leung, J; Cameron, A D;
Byrne, B; Iwata, S and Drew, D (2011). Benchmarking membrane protein detergent stability for improving throughput of high-resolution X-ray structures. Structure, 19: 17-25.

Takahashi, R; Nishio, $\mathrm{T}$; Ichizen, $\mathrm{N}$ and Takano, $\mathrm{T}$ (2007). Cloning and functional analysis of the $\mathrm{K}^{+}$ transporter, PhaHAK2, from salt-sensitive and salttolerant reed plants. Biotechnology Letters, 29: 501506.

Takano, J; Noguchi, K; Yasumori, M; Kobayashi, M; Gajdos, Z; Miwa, K; Hayashi, H; Yoneyama, T and Fujiwara, T (2002). Arabidopsis boron transporter for xylem loading. Nature, 420: 337-340.

Tate, C G; Haase, J; Baker, C; Boorsma, M; Magnani, F; Vallis, Y and Williams, D C (2003). Comparison of seven different heterologous protein expression systems for the production of the serotonin transporter. Biochim. Biophys. Acta, 1610: 141-153.

Ubarretxena-Belandia, I and Stokes, D L (2010). Present and future of membrane protein structure determination by electron crystallography. Adv. Protein Chem. Struct. Biol., 81: 33-60.

Van Criekinge, W and Beyaert, R (1999). Yeast twohybrid: State of the art. Biol. Proced. Online, 2: 1-38.

Villalba, J M; Palmgren, M G; Berberian, G E; Ferguson, C and Serrano, R (1992). Functional expression of plant plasma membrane $\mathrm{H}(+)$-ATPase in yeast endoplasmic reticulum. J. Biol. Chem., 267: 12341-12349.

Wang, Y H (2002). Rapid induction of regulatory and transporter genes in response to phosphorus, potassium, and iron deficiencies in tomato roots. Evidence for cross talk and root/rhizospheremediated signals. Plant Physiology, 130: 1361-1370.

Wang, D N; Safferling, M; Lemieux, M J; Griffith, H; Chen, Y and Li, X D (2003). Practical aspects of overexpressing bacterial secondary membrane transporters for structural studies. Biochim. Biophys. Acta, 1610: 23-36.

Yildirim, M A; Goh, K I; Cusick, M E; Barabasi, A L and Vidal, M (2007). Drug-target network. Nat. Biotechnol., 25: 1119-1126. 